\title{
Corrigendum
}

Otto Lerke* and Volker Schwieger

\section{Corrigendum to: Analysis of a kinematic real-time robotic total station network for robot control}

https://doi.org/10.1515/jag-2021-2002

Corrigendum to: Otto Lerke and Volker Schwieger. September 2021. Analysis of a kinematic real-time robotic total station network for robot control. Journal of Applied Geodesy. Volume 15, Issue 3, pages 169-188. (https://doi.org/ 10.1515/jag-2021-0016):
The article mistakenly was published with the wrong article category "Review". It is now replaced with the correct article category "Research Article". For the reader's convenience, the correction appears below again.

Research Article

*Corresponding author: Otto Lerke, University of Stuttgart, Faculty Aerospace Engineering and Geodesy, Institute of Engineering Geodesy, Stuttgart, Germany, e-mail: otto.lerke@iigs.uni-stuttgart.de Volker Schwieger, University of Stuttgart, Faculty Aerospace Engineering and Geodesy, Institute of Engineering Geodesy, Stuttgart, Germany 